tained, but kite flying is an art of which we were then without previous experience, and so it was well to err on the safe side. A steam vessel is extremely convenient for kite flying, as by altering either her speed or direction the strain upon the wire, provided the vessel is not already going full speed against or with the wind, can be varied with the utmost nicety.

With more than two kites difficulties often occur owing to the fact that very different wind velocities may prevail at different heights. If the wind is greatest at the surface, adding more kites does not add appreciably to the height of the end one, since no kite can rise into a stratum in which it does not find sufficient wind. This sometimes occurred, but the more usual case was that the wind force increased too rapidly with elevation, so that if the tug were used to increase the relative surface wind to suit the lower kites, it added too much to the strength of the upper wind, and by unduly increasing the force upon the upper kites, put a dangerously high tension upon the wire. If, on the other hand, the tug were moved to suit the upper kites, the lower ones might be becalmed, and useless for lifting purposes, or perhaps even fall into the sea.

Very interesting results have been obtained from these experiments, both in America and on the Continent, but it has been felt that the conditions prevailing over the large oceans are very likely different from those over the continents. The cyclonic disturbances, on the motion of which our weather very largely depends, certainly show a preference for the sea, and it was in the hope that some light might be thrown on their mechanism, and the causes which produce them, that a locality on the west coast of Scotland was chosen for the observations. The evidence obtained from last summer's work is not sufficient to be conclusive, but so far as it goes it tends to show that as a depression approaches, the decrease of temperature with elevation becomes less than it was before. This was the case with every depression that passed while the experiments were in progress, and it leads to the conclusion that the upper air in the neighbourhood of a cyclone is relatively warm, and that the cyclones are convectional effects.

A further result of the observations shows that the temperature of Ben Nevis was in every instance below that of the free air at the same level some sixty miles to the south-west, often from $5^{\circ}$ to $8^{\circ} \mathrm{F}$. below. That the two air temperatures should have agreed was hardly expected, but the difference was very marked, and it is desirable that the experiments should be repeated in the same locality to confirm the result. The fact, however, that the summit of the mountain is so often wrapped in clouds, when the sky is clear elsewhere, tends to show that the summit must be unduly cold, and it seems likely that the effect is produced by the adiabatic cooling of the air as it is forced up the mountain slope. In fact, the cloud level on all the mountains and hills in the neighbourhood was always much below the point at which the kites entered the clouds. It is also known from the differences in the barometer on the Ben and the values computed from the Fort William readings that the temperature of the intermediate layers of air is not truly represented by the mean derived from the summit and sea-level temperatures.

England being so near the usual cyclonic tracks, observations on the upper air are of especial interest, and it is very desirable that a permanent station for the purpose should be established. It may perhaps be found that unmanned balloons too often fall into the sea to be usefully employed, but the attempt is well worth a trial, and so far as kite observations are concerned, the only difficulty is the financial one.

W. H. Dines.
A NATIONAL DIPLOMA IN AGRICULTURE. SO-CALLED national diploma in the science and practice of agriculture can now be obtained by any student who passes the necessary examinations. This diploma has undoubtedly a high-sounding title-it would be difficult indeed to suggest a title of greater weight-and it is therefore not surprising that the number of students entering each year for the examination is steadily increasing, and that successful students should be proud to write the important letters N.D.A. after their names. Now we greatly wish that a truly national diploma in agriculture could be obtained; that a well-ordered scheme of education and examination were authoritatively set forth; and that the skill and knowledge of the nation should be really brought to bear upon the subject. The diploma in question has no right to the title of "national." It is granted by a joint committee of two agricultural societies-the Royal Agricultural Society of England and the Highland and Agricultural Society of Scotland-it should therefore be designated "the agricultural societies' diploma." To claim for it a national importance, and thus to imply that it ranks above all other agricultural diplomas, is simply to mislead the public, and to assert a position to which it has absolutely no right. The question of continuing to grant the diploma in question has lately entered a critical stage; it may be of service, therefore, to set forth in few words the origin and character of the examinations on which it is based.

It must be reckoned as greatly to the credit of the two agricultural societies we have just named that they have been for many years engaged in promoting agricultural education by means of examinations. The Highland and Agricultural Society of Scotland was at the pains to obtain a supplementary charter in 1856 in order that it might add agricultural education to the other functions of the Society. This charter sets forth that "in order to encourage the proper education of agriculturists in Scotland " the Society is empowered to appoint a committee consisting of the professors of agriculture, anatomy, botany, chemistry, natural history, and technology in the University of Edinburgh, with sundry public officials, and seven members chosen by the Society. This committee is to appoint a board of examiners, and to grant diplomas bearing the corporate seal of the Society. The Society has acted on the powers thus given; it has conducted annual examinations in Edinburgh from $185^{8}$ to 1899 , and granted diplomas according to the terms of its charter.

The Royal Agricultural Society of England possesses no such definite authority as that given to the Highland Society for the conduct of examinations or the granting of diplomas; its charter, given in 1840 , merely authorises it " to take measures for the improvement of the education of those who depend upon the cultivation of the soil for their support." The Society has conducted annual examinations in England from 1868 to 1899 . Up to 1897 the successful candidates received certificates, but in 1898 and $r 899$ diplomas were granted.

In 1897 the two societies nominated a joint board of examiners to conduct examinations in the science and practice of dairying, and annual examinations have since been regularly held both in England and Scotland. The successful candidates receive a national diploma in the science and practice of dairying.

In I 899 the two societies took a further step, and appointed a joint board of examiners to conduct examinations in the science and practice of agriculture; the examinations hitherto conducted by the separate societies then ceased. The first examination by the joint board was held in 1900 , and such examinations 
have since been regularly continued. The examination is always held in England. The successful candidates receive a national diploma in the science and practice of agriculture.

Such, then, is the history of the diploma of which we are at present speaking. It is, of course, obvious that any society or societies may hold an examination in any subject they please, and grant certificates to successful candidates; but may such bodies, without proper authority, presume to confer a national diploma? That is the serious question before us. The charter of the Highland Society undoubtedly authorises it to confer a diploma in agriculture in Scotland, but the language of its charter, which we have already quoted, clearly limits its authority to that country. This fact is so manifest that we are now told by the agricultural Press that the Highland Society intends to apply to His Majesty's Government for an extension of its charter. The charter of the English Society contains no authority to grant diplomas.

We have already said that a national diploma in agriculture appears to us as a desirable thing, if it could be granted by national authority and awarded only to thoroughly trained men. If powers to grant such a diploma are now being sought, the terms of the charter granted many years ago to the Highland Society supply some pertinent suggestions. If the diploma is to be really national, if it is to be stamped with a national authority, the schemes of education and examination laid down must not be decided on by the members of two agricultural societies. The charter of the Highland Society names six professors of the University of Edinburgh as members of the education committee. A charter granted with a similar object now would naturally take a similar line, but it would not limit itself to the University of Edinburgh. The ex officio members of a national committee should clearly include professors from other British Universities, and representatives of the Government Boards of Agriculture and Education. Until such a general body is constituted and authorised to grant diplomas, it is a misuse of language to speak of a national diploma in agriculture or dairying.

We turn now to the character of the examination at present held for the award of the so-called national diploma. If the diploma granted merely professed to be an agricultural societies' diploma, it would be scarcely necessary to speak on the subject; but the claim to national rank surely implies a diploma examination of first-rate quality, and if it fails of this it certainly demands public criticism.

The diploma in question is granted solely on the result of examinations, no previous course of training being required. The examinations for the diploma embrace many branches of elementary science; half of the subjects are taken by the candidate in his first year and half in his second year. The syllabuses published of the subjects for examination are undoubtedly meagre, some of them strikingly so. This is a real disadvantage, as the teachers who are preparing students for these examinations naturally limit their instructions to the syllabus. The examinations are both written and oral, but include no laboratory work. In each subject the written examination is limited to two hours, save in the case of practical agriculture to which three hours are allotted. The candidates are generally directed to attempt every question in the paper, six to ten questions being set. The whole of the subject of practical agriculture is dealt with in one paper of three hours, followed by an oral examination. The tests applied by the examiners would thus appear to be decidedly superficial. The number of marks allotted to each subject must be sup- posed to indicate their relative importance in the eyes of the examining board. We find that book-keeping and agricultural chemistry receive the same number of marks, while general chemistry and veterinary science each receive half as many marks as book-keeping! It is, indeed, essential that anyone who is to practise tarming should pass an examination in book-keeping, but that a knowledge of agricultural chemistry should be taken to represent no greater previous study or no greater fitness for dealing with the problems of agriculture than a mastery of the art of posting trade accounts is certainly remarkable, and surely indicates a low appreciation of agricultural science by the examining board.

We have now done. The questions we have raised demand earnest attention. The character of our whole system of agricultural education depends on the standard set by what is apparently its highest grade. The present diploma has been given a title to which it has no right, and it has failed to justify by its excellence the rank which has been sought for it.

\section{THE INTERNATIONAL CONGRESS FOR APPLIED CHEMISTRY.}

THE fifth International Congress for Applied

Chemistry, which sat in the Reichstags-Gebäude of Berlin from June 2 to 8 under the masterly presidency of Dr. Otto N. Witt, professor at the Technical High School of Charlottenburg, will be remembered as a great representative meeting. The actual attendance figure was not announced, probably because many of the members who had previously secured their tickets forgot to enter their names on arrival. But the figure cannot much fall short of 2700 . Preparations had originally been made for I500 members. About 2500 had arrived by the time of the opening of the Congress, and those joining later could not be favoured with invitations to the many pleasant receptions and excursions which had been arranged. Everything possible was, however, done by the local committee, over which Dr. J. E. Holtz presided, and by the general secretaries, Dr. Pulvermacher and T. Karwath. Everybody could gain admission to the grand "Commers." The Diet had made a grant of $x_{5}, 000$ marks, donations had poured in from many sides, and private hospitality was practised most liberally. Chemical works, in the strict sense of the word, were not opened to members, but visits to special exhibitions, scientific institutes, and manufactories would have supplied an amply long and instructive programme even if the sectional proceedings had left members far more spare time than they did. Some sections deliberated from 9 to $x$, and again from 3 to 6 and later. The ladies were excellently taken care of during the whole congress week.

Though a more suitable and dignified place for the meeting could not have been found than the magnificent palace of the Imperial Diet, the large committee rooms of which afforded ample accommodation for all the sections, a parliament building is not a laboratory, and some of the sections had to emigrate for their experimental demonstrations. Section vii., fermentation and starch, sat mostly in the Institute for Fermentation, and had an exhibition of its own in the grounds adjoining this institute. Section ix., photochemistry, was isolated-and rather neglected, tooin the Technical High School at Charlottenburg. Section x., electrochemistry and physical chemistry, found a home in the Physical Institute of the University, close to the Reichstag. Each section had its official luncheon restaurant. The plenary meetings took place in the large hall of the Reichstag. 